\title{
IMPORTANCE OF ORGANISATIONAL CLIMATE IN CONTEMPORARY MANAGEMENT
}

\author{
Jain Mathew* and Uma Selvi**
}

ABSTRACT:
Organizational climate can be defined as shared perceptions or
prevailing organizational norms for conducting workplace activities.
The term organizational climate to the psychological conditions
prevailing in the organization refers to behaviors, attitudes, and feelings
that are common there. Organizational climate influences to a great
extent the performance of the employees because it has a major impact
on motivation and job satisfaction of individual employees.
Organizational climate determines the work environment in which the
employee feels satisfied or dissatisfied. Since satisfaction determines
or influences the efficiency of the employees, we can say that
organizational climate is directly related to the efficiency and
performance of the employees. The factors that can be observed and
measured are called overt factors and the factors that are not visible

* Faculty of Management Studies, Christ College, Bangalore.

Email:jainmathew@christcollege.edu

** Faculty of Management Studies, Cauvery College for Women, Thiruchirappally. 
and quantifiable are called covert factors. Overt factors of organizational climate are: Hierarchy, Financial resources, Goals of organizations, Skills and abilities of personnel, Technological state, Performance standards and Efficiency measurement. Covert factors of organizational climate are: Attitudes, Feelings, Values, Norms, Interaction, Supportiveness and Safisfaction. The lechniques that are generally helpful in improving the climate of the organization are: Effective Communication System, Concern for people, Participative decision making, Change in policies, Procedures and rules and Technological changes. A climate that favors risk taking will encourage employees to test and exchange unusual knowledge and ideas. Participation is a very effective tool to develop sound organizational climate and job satisfaction. More satisfied employees possess some personality characteristics that are likely to be reflected in good work performance, self-efficacy and locus of control. An atmosphere of cooperation opens access among group members and creates individual motivation to exchange knowledge with group members resulting in more productivity. So the managements of corporations should strive to create a congenial organizational climate in the organizations.

\section{Organisational Climate}

\section{Introduction}

The ferm organizational climate to the psychological conditions prevailing in the organization refers to behaviors, attifudes, and feelings that are common there. Climate acts its role by influencing organizational processes such as problem solving; decision making; planning; communication; coordination and controlling; and psychological processes of learning, identification, motivation, and so on. By way of such influences the climate becomes a modifying force that can enlarge or reduce the effects of the organization's investments and operations; it is an intervening variable between input and output.

The climate evolves in the confrontation between the staff members and organizational realities, structures, policies, tasks, goals, strategies, leadership, resources, workload, technology, and staff characteristics. Those situational factors are the determinants of the climate. The people in the organization are wearers and exponents of the climate but also situational determinants. One staff member is a situational reality for other staff members and vice versa. 
The climate thus influences organizational outcomes. Situational realities influence the climate, but they also influence the organization's results of different kinds. Important questions from both theoretical and practical aspects were how much organizational realities influence outcomes in a direct way, and how much goes by way of the climate. This kind of question has garnered very little attention in organization research.

Climate of an organization is somewhat like the personality of a person. Just as every individual has a personality that makes him unique and different from other persons. Each organization has an organizational climate that clearly distinguishes it from other organizations. Basically, the organizational climate reflects a person's perception of the organization to which he belongs. It is a set of unique characteristics and factures that are perceived by the employees about their organizations, which serves as a major force in influencing their behaviour. Thus, organizational climate in a broad sense can be understood as the social setting of the organization.

\section{Meaning and Definition}

Organizational climate can be defined as shared perceptions or prevailing organizational norms for conducting workplace activities (Reichers \& Schneider, 1990). Scholars have agreed that organizational climate is a function of the way employees perceive elements of the work setting including both internal (struclure, power distribution, supervisory practices etc.) and external factors (social, economic, legal, etc.). Organizational climate theory also assumes that individuals are influenced by how others respond to conditions in their environment; thus, an individual will behave in a similar manner (Reichers \& Schneider, 1990). Organizational climate mirrors to some degree the expectations of top management. Rousseau (1988) suggests that different climates can exist within the same firm, and Reichers and Schneider (1990) state that climate in one department may differ from that in another. These differences may be attributed to differences in expectations set by management, employee perceptions, or an interaction of the two. Successful organizations today foster an organizational climate characterized by continuous improvement as a way of life through encouragement, creative, harmonious and team oriented attitudes (Beer, Eisenstat, \& Spector, 1990). Such attitudes may be related to an individual's level of organization-based self-esteem (Pierce, Gardner, Cummings, \& Dunham, 1989). Organizational climate is an enduring characteristic that distinguishes one organization from another (Moran \& Volkwein, 1992).

Organizational climate has been defined as a "perception of the psychologically important aspects of the work environment" (Ashforth, 1985) and is recognized as a potential influence on employees' workplace behavior and job satisfaction 
(Ashforth, 1985). The individual worker's perception of their work environment rather than a consensus view is considered as different individuals may perceive the same workplace in different ways (Klein, Conn, Smith, \& Sorra, 2001). Climate consists of a set of characteristics that describe an organization, distinguish it from other organizations are relatively enduring over time and influence the behaviour of people in it.

According to Campbell (1970) "Organizational climate can be defined as a set of attributes specific to a particular organization that may be induced from the way that organization deals with its members and its environment. For the individual members within the organization, climate takes the form of a set of attitudes and experiences which describe the organization in terms of both static characteristics (such as degree of autonomy) and behaviour outcome and outcome-outcome contingencies."

Thus, organizational climate is a relatively enduring quality of the internal environment that is experienced by its members, influences their behaviour and can be described in terms of the value of a particular set of characteristics of the organization. It may be possible to have as many climates as there are people in the organization when considered collectively, the actions of the individuals become more meaningful for viewing the total impact upon the climate and determining the stability of the work environment. The climate should be viewed from a total system perspective. While there may be differences in climates within departments these will be integrated to a certain extent to denote overall organizational climate.

\section{Characteristics of Organizational Climate}

The nature of organizational climate will be clear from the following characteristics.

1. General Perception- Organizational climate is a general expression of what the organization is. It is the summary perception, which people have about the organization. It conveys the impressions people have of the organizational internal environment within which they work.

2. Abstract and Intangible Concept- Organizational climate is a qualitative concept. It is very difficult to explain the components of organizational climate in quantitative or measurable units.

3. Unique and Distinct Identity- Organizational climate gives a distinct identity to the organization. It explains how one organization is different from other organizations. 
4. Enduring Quality- Organizational climate builds up over a period of time. It represents a relatively enduring quality of the internal environment that is experienced by the organizational members.

5. Multi-dimensional Concept- Organizational climate is a multi-dimensional concept. The various dimensions of the organizational climate are individual autonomy, authority structure, leadership style, pattern of communication, degree of conflicts and cooperation etc.

\section{Factors Influencing Organizational Climate}

Organizational climate is the manifestation of the attitudes of organizational members towards the organization. Researchers have used the data relating to individual perception of organizational properties in identifying organizational climate. Even in this context, there is a great amount of diversity.

LITWIN and STRINGER (1968) have included six factors which affect Organizational climate. These factors are:

(i) Organizational Structure- Perceptions of the extent of organizational constraints, rules, regulations, red tape.

(ii) Individual Responsibility- feeling of autonomy of being one's own boss.

(iii) Rewards-feelings related to being confident of adequate and appropriate rewards.

(iv) Risk and Risk Taking - perceptions of the degree of challenge and risk in the work situation.

(v) Warmth and Support. feeling of general good fellowship and helpfulness prevailing in the work setting.

(vi) Tolerance and Conflict - degree of confidence that the climate can tolerate, differing opinions.

SCHNEIDER and BARLETT (1990) give a broader and systematic study of climate dimensions. They include the following factors:

(I) Management Support.

(ii) Management Structure. 
(iii) Concern fornew employees

(iv) Inter-agency conflict.

(v) Agent dependence and

(vi) General Satisfaction

TAGUIRI (1968) has identified five factors influencing the organizational climate on the basis, of information provided by managers. These are:

(i) Practices relating to providing a sense of direction or purpose to their jobssetting of objectives, planning and feedback.

(ii) Opportunities for exercising individual initiative.

(iii) Working with a superior who is highly competitive and competent.

(iv) Working with cooperative and pleasant people.

(v) Being with a profit oriented and sales oriented company.

LAWRENCE JAMES AND ALLAN JONES (1974) have classified the following factors that influence organizational climate:

(i) Organizational Context- mission, goals and objectives, function etc.

(ii) Organizational Structure -size, degree of centralization and operating procedures.

(iii) Leadership Process- Leadership styles, communication, decision making and related processes.

(iv) Physical Environment- employee safety, environmental stresses and physical space characteristics.

(v) Organizational Values and Norms- conformity, loyalty, impersonality and reciprocity.

Factors of organizational climate - The factors that can be observed and measured are called overt factors and the factors that are not visible and quantifiable are called covert factors. Overt factors are: Hierarchy, Financial resources, Goals of organizations, Skills and abilities of personnel, Technological state, Performance standards and Efficiency measurement. Covert factors are: Attitudes, Feelings, Values, Norms, Interaction, Supportiveness and Satisfaction. 


\section{Impact of Organizational Climate}

Organizational climate influences to a great extent the performance of the employees because it has a major impact on motivation and job satisfaction of individual employees. Organizational climate determines the work environment in which the employee feels satisfied or dissatisfied. Since satisfaction determines or influences the efficiency of the employees, we can say that organizational climate is directly related to the efficiency and performance of the employees.

The organizational climate can affect the human behaviour in the organization through an impact on their performance, satisfaction and attitudes. There are four mechanisms by which climate affects the behaviour of the employees.

1. Constraint System. Organizational climate can operate as a constraint system in both the positive and negative sense. Providing information to the employees about what kind of behaviour will be rewarded, punished or ignored can do this. Thus, behaviour can be influenced by varying degrees of rewards and punishments. Such a constraint system would influence the behaviour of those people who are most interested in those specific values, which are assigned to different behavioural outcomes.

2. Evaluation of Self and Others. Organizational variables may affect behaviour through evaluation of self and others. In this evaluation process both the physiological and psychological variables will be associated. Such evaluation will affect the human behaviour.

3. By Acting as Stimuli. Organizational factors can influence human behaviour by acting as stimuli. As stimuli they influence individual's arousal level, which is a motivational variable directing human behaviour. The level of arousal will directly affect the level of activation and hence performance.

4. By Helping the Individual to Form a Perception. Organizational factors influence the behaviour by helping the individual in forming a perception of the organization. The perception then influences behaviour.

\section{Dimensions of Organizational Climate}

Organizational climate is a multi dimensional concept. The important dimensions or components, which collectively represent the climate of an organization, are discussed below.

1. Dominant Orientation. Dominant orientation of the organization is an important determinant of climate and it is the major concern of its members. If the 
dominant orientation is to adhere to established rules and regulations, the climate is characterised by control. If the orientation is to produce excellence the climate will be characterised by achievement.

2. Inter-Personal Relationships. The interpersonal relationships in the organizations are reflected in the way informal groups formed and operated. The informal groups may benefit the organization also, but in some cases it may displace the goals of the organization.

3. Conflict Management. In the organization, there can always be inter-group as well as intra group conflicts. The organizational climate will depend upon how effectively these conflicts are managed. If they are managed effectively, there will be an atmosphere of cooperation in the organization. If they are not managed properly there will be an atmosphere of distrust and non-cooperation.

4. Individual Autonomy. If the individual employees are given sufficient freedom to work and exercise authority, it will result in efficiency in operations. The autonomy will lighten the burden of higher-level executives.

5. Organizational Control System. The control system of the organization can be either rigid or flexible. Rigid control will lead to impersonal or bureaucratic atmosphere in the organization. There will be minimum scope for self-regulation.

6. Organizational Structure. The organizational structure serves the basis of inter personal relations between superiors and subordinates. It clarifies as to who is responsible to whom and who is to direct to whom. If there is centralisation of authority, the participation in decision making by the subordinates will be very less. On the other hand, if there is decentralization of authority, there will be an atmosphere of participative decision-making.

7. Task Oriented or Relations Oriented Management. The dominant style of managers will also affect the organizational climate. Task oriented approach means that the leadership style will be autocratic. The employees will have to show results or face the punishment. The employee morale will be low in the long run.

If the managers are relations oriented, the climate will be considerate and supportive. There will be team spirit in the organization because the needs and aspirations of the workers will be given due importance.

8. Rewards and Punishments. The system of rewards and punishments is also an important component of organizational climate. If the reward system is directly related to performance and productivity, there will be an atmosphere of competition among the employees. Everybody will like to work hard and earn more reward in 
the form of promotions and pay rise. If there is biasedness in the distribution of rewards, the meritorious employees will be discouraged.

9. Communication. The communication system of the organization will also affect the organizational climate. The flow of information, its direction, its dispersement and its type are important determinants. Proper communication system means that the subordinates are in a position to express their ideas, suggestions and reactions, otherwise they will feel frustrated.

10. Risk Taking. How members respond to risks and whose help is sought in situations involving risks are important in any organization. If individuals feel free to try out new ideas without any fear they will not hesitate in taking risks. Such an atmosphere will be conducive to innovative ideas. .

The above dimensions or components are not mutually exclusive, they often overlap each other. The way in which these different dimensions operate an organization indicates the underlying philosophy of the management.

\section{Developing a Sound Organizational Climate}

To develop a sound organizational dimate is a long term proposition. Organizational climate depends upon the organizational behaviour system. The organizational climate should represent the goals and philosophies of those who join together to create the organization. The type of climate that an organization seeks is contingent upon the type of people it has, the type of technology, level of education and expectations of people in it. The following techniques are generally helpful in improving the climate of the organization.

1. Effective Communication System. There should be a two way communication in the organization so that the employees know what is going on and react to it. The manager can modify his decision on the basis of feedback received.

2. Concerns For People. The management should be interested in the human resource development. It should work for the welfare of employees and an improvement in their working conditions. For developing a sound organizational climate, the management should have shown concern for the people.

3. Participative Decision Making. The management should involve the employees in decision-making process, particularly those decisions that are related to goal setting and affect them. Participative decision-making will make the employees committed to the organization and more co-operative also. 
4. Changes in Policies, Procedures and Rules. Making changes in the policies, procedures and rules can also change the organizational climate. It is a time consuming process but the changes will also be long lasting if the workers see the changes in policies, procedures and rules as favorable to them.

5. Technological Changes. Generally, the workers and employees resist any innovative changes. But where technological changes improve the working conditions of the employees, the change will be easily accepted. Better climate will be there if the management adopts innovative changes in consultation with the employees.

But all the above factors are contingent upon the assumptions of the nature of people in general. For example, the ECONOMIC MAN is basically motivated by money and economic security and hence, economic factors may be used to attract and motivate him. For a SOCIAL MAN positive social relations and interactions are a must. Thus, the creation of a climate where happy family atmosphere prevails is appropriate for him. The SELF ACTUATING MAN seeks achievement, accomplishment and meaning in what he does. The organizational climate with a certain degree of freedom is appropriate for him.

In order to build up a sound organizational climate, management must understand the people in the organization. The importance must be given to what motivates people's performance in general and building an overall climate conducive to motivation, a keen insight into the individual in particular and tailoring a personal approach to leadership and job design to which the man will respond with commitment. Researchers are of the opinion that there cannot be any all-purpose organizational climate.

\section{Conclusion}

Various research studies confirm the positive relationship between organizational climate and employee performance. A climate that favors risk taking will encourage employees to test and exchange unusual knowledge and ideas. Weick and Westley (1996) proposed that a climate emphasizing rules and controls would push an organization toward order and away from learning and new knowledge creation. In contrast, a climate that stresses risk taking and experimentation will move the organization toward disorder and experimentation that leads to new knowledge creation. For exchange and combination to occur, organization members must perceive the willingness of the organization to experiment with new ideas and to take risks in both their development and implementation (Nahapiet \& Ghoshal, 1998). Although a climate for risk taking may be important for new knowledge creation, it is also important that norms of cooperation and teamwork exist in an 
organization for exchange and combination to occur. Nahapiet and Ghoshal (1998) argued that an atmosphere of cooperation opens access among group members and creates individual motivation to exchange knowledge with group members. Starbuck (1992) described how norms for openness and teamwork in knowledge-intensive firms facilitated disclosure of information and loyalty building. Tushman and $O^{\prime}$ Reilly (1997) found that a climate of teamwork was key to effective creativity, and Amabile (1988) found that creativity was hurt when an organization's climate was characterized by a lack of cooperation. Participation is a very effective tool to develop sound organizational climate and job satisfaction. More satisfied employees possess some personality characteristics that are likely to be reflected in good work performance, self-efficacy and locus of control. So the managements of corporations should strive to create a congenial organisational climate in their organizations.

\section{References}

1. Ashkenasy, N. M., Wilderom, C. P. M., \& Peterson, M. F. (Eds.) (2000). Handbook of organizational culture and climate. London: Sage.

2. Denison, D. R. (1996). What is the difference between organizational culture and organizational climate? A native's point of view on a decade of paradigm wars. Academy of Management Review, 21, 619-654.

3. Eagly, A. H., \& Chaiken, S. (1993). The psychology of attitudes. Orlando, FL: Harcourt Brace Jovanovich.

4. Hackman, J.R., \& Oldham, G. (1976). Motivation through the design of work: Test of a theory. Organizational Behavior and Human' Performance, 16, 250-279.

5. Payne, R. L. (2000). Climate and culture: how close can they get? In N. M. Ashkenasy, C. P. M. Wilderom, \& M. F. Peterson (Eds.), Handbook of organizational culture and climate (pp. 163-176). London: Sage.

6. Reichers, A. E., \& Schneider, B. (1990). Climate and culture: An evolution of constructs.

7. Schneider, B. (Ed.) (1990). Organizational dimate and culture. San Francisco, CA: Jossey-Bass.

8. James, L. R., \& Jones, A. P. (1974). Organizational climate: A review of theory and research. Psychological Bulletin, 81, 1096-1112.

9. Kozlowski, S. W. J., \& Hults, B. M. (1987). An exploration of climates for technical updating and performance. Personnel Psychology, 40, 539-563. 
10. Denison, D.R. (1996). What is the difference between organizational culture and organizational dimate? A native's point of view on a decade of paradigm wars. Academy of Management Review, 21, 619-654.

11. Moran, T.E. \& Volkwein, F.J. (1992). The Cultural Approach to the Formation of Organizational Climate. Human Relations, 45, 19-47.

12. Reichers, A., \& Schneider, B. (1990). Climate and culture. In Schneider, B. (ed.) Organizational Climate and Culture. San Francisco: Jossey-Bass

13. Rousseau, D. (1988). The construction of climate in organizational research. In Cooper and Robertson (Eds). International Review of Industrial and Organizational Psychology.

14. Amabile, T., \& Gryskiewicz, N. D. (1989). The Creative Environment Scales: Work Environment Inventory. Creativity Research Journal, 2, 231-253.

15. Ekvall, G. (1988). Arbetsklimatet: Manual formular A The working climate: Manual A]. Stockholm, Sweden: G. E. Organsational psychology.

16. Ekvall, G. (1991). The organizational culture of idea management: A creative climate for the management of ideas. In J. Henry \& D. Walker (Eds.), Managing innovation (pp. 73-79). London: Sage.

17. Ekvall, G. (1996). Organizational climate for creativity and innovation. European Work and Organizational Psychology, 5, 105-123.

18. Isaksen, S. G. (1995, October). Some recent developments on assessing the climate for creativity and change. Paper presented at the International Conference on Climate for Creativity and Change, Center for Studies in Creativity, Buffalo, NY.

19. Madu, C.N., Kuei, C. \& Lin, C. (1995) A comparative analysis of quality practice in manufacturing firms in the U.S. and Taiwan, Decision Science, 26, pp. 621-635.

20. Ostroff, C. (1993) The effects of climate and personal influences on individual behavior and altitudes in organization, Organizational Behavior and Human Decision Processes, 56, pp. 56-90.

21. Blau, G. (1995). Influence of group lateness on individual lateness: A cross-level examination. Academy of Management Journal, 38: 1483-1496.

22. Bartram. D., Robertson, I. T., \& Callinan, M. (2002). A framework for examining organizational effectiveness. In I. T. Robertson, M. Callinan, \& D. Bartram (Eds.), Organizational effectiveness: The role of psychology (pp. 1-10). Chichester: Wiley. Organizational climate and company productivity 213

23. Denison, D.R. (1996). What is the difference between organizational culfure and organizational climate? A native's point of view on a decade of paradigm wars. Academy of Management Review, 21: 619-654. 
24. Glick, W.H. (1985). Conceptualizing and measuring organizational and psychological climate: Pitfalls in multilevel research. Academy of Management Review, 10:601 616.

25. Hofmann, D.A., \& Stetzer, A. (1996). A cross-level investigation of factors influencing unsafe behaviors and accidents. Personnel Psychology, 49: 307-339.

26. James, L.A., \& James, L.R. (1989). Integrating work environment perceptions: Explorations into the measurement of meaning. Journal of Applied Psychology 74: 739-751.

27. James, L.R., James, J.A., \& Ashe, D.K. (1990). The meaning of organizations: The role of cognitions and values. In Schneider, B. (Ed.), Organizational climate and culture (pp. 40-84). San Francisco: Jossey-Bass.

28. James, L.R., \& Jones, A. P. (1974). Organizational climate: A review of theory and research. Psychological Bulletin, 81: 1096-1112.

29. James, L.R., Joyce, W.F., \& Slocum, J.W. (1988). Comment: Organizations do not cognize. Academy of Review, 13:129-132.

30. Martocchio, J.J. (1994). The effects of absence culture on individual absence. Human Relations, 47: 243-262.

31. Roberts, K.H., Hulin, C.L., \& Rousseau, D. M. (1978). Developing an interdisciplinary science of organizations. San Francisco: Jossey-Bass.

32. Schneider, B. (1987). The people make the place. Personnel Psychology, 40: 437 453.

33. Schneider, B. (1990). The climate forservice: An application of the climate construct. In Schneider, B. (Ed.), Organizational climate and culture (pp. 383-412). San Francisco: Jossey-Bass.

34. Schneider, B., Parkington, J.J., \& Buxton, V.M. (1980). Employee and customer perceptions of service in banks. Administrative Science Quarterly, 25: 252-267.

35. Waldman, D.A. (1993). A theoretical consideration of leadership and total quality management. Leadership Quarterly, 4: 65-79.

36. Waldman, D.A. (1994). The contributions of total quality management to a theory of work performance. Academy of Management Review, 19: 510-536.

37. Blumer, H. 1969. Symbolic interactionism: Perspective and method. Englewood Cliffs, NJ: Prentice-Hall.

38. Glick, W. H. 1985. Conceptualizing and measuring organizational and psychological climate: Pitfalls in multilevel research. Academy of Management Review, 10: $601-616$. 
39. James, L. R., \& Jones, A. P. 1980. Perceived job characteristics and job satisfaction: An examination of reciprocal causation. Personnel Psychology, 33: 97-135.

40. James, L. R., \& Tetrick, L. E. 1986. Confirmatory analytic tests of three causal models relating job perceptions to job satisfaction. Journal of Applied Psychology, 71: 77-82

41. Newman, J. 1975. Understanding the organizational structure-job attitude relationship through perceptions of the work environment. Organizational Behavior and Human Performance, 14:371-397.

42. Payne, R. 1990. Madness in our method: A comment on Jackofsky and Slocum's paper "A longitudinal study of climates." Journal of Organizational Behavior, 11 : 77-80.

43. Schneider, B. 1990. The climate for service. An application of the climate construct. In B. Schneider (Ed.), Organizational climate and culfure: 383-412. San Francisco: Jossey-Bass.

44. Schneider, B., \& Reichers, A. E. 1983. On the etiology of climales. Personnel Psychology, 36: 19-39. 